\title{
Head injury
}

\author{
J Douglas Miller
}

Head injury is one of the commonest disorders seen by doctors in hospital. It is therefore regrettable that in much of the United Kingdom today an unjustifiably pessimistic view about head injury continues to prevail. In fact, there have been major steps forward in understanding pathophysiology, facilitating diagnosis and organising management of head injury. These have produced a $15-20 \%$ reduction in mortality following severe (coma producing) head injury with no increase in severe disability among survivors, and there is a strong indication that further improvements are possible. Determination of risk factors for secondary deterioration and a pre-emptive approach to management are important. Wider awareness of recent advances in thinking about traumatic brain injury is necessary so that resources can be appropriately allocated.

\section{Epidemiology of head injury}

Between 2000-3000 per million population are admitted to hospital each year because of head injury. For each patient admitted, 3 or 4 others have been seen in the Accident and Emergency Department of the hospital or in the general practitioner's surgery and allowed home. ${ }^{12}$

Of those admitted to the hospital, approximately $5 \%$ or 100 per million per year, are suffering from severe head injury-in coma, scoring 8 or less on the Glasgow Coma Scale with no eye opening, even to pain (table 1).

Table 1 Glasgow Coma Scale for assessment of level of consciousness

\begin{tabular}{ll}
\hline EYE OPENING (E) & \\
Spontaneous & 4 \\
To command & 3 \\
To pain & 2 \\
Nil & 1
\end{tabular}

BEST MOTOR RESPONSE (M)

\begin{tabular}{|c|c|}
\hline $\begin{array}{l}\text { Obeys commands } \\
\text { Localised pain } \\
\text { Normal flexion } \\
\text { Abnormal flexion } \\
\text { Extension } \\
\text { Nil }\end{array}$ & $\begin{array}{l}6 \\
5 \\
4 \\
3 \\
2 \\
1\end{array}$ \\
\hline \multicolumn{2}{|c|}{ VERBAL RESPONSE (V) } \\
\hline $\begin{array}{l}\text { Orientated speech } \\
\text { Disorientated speech } \\
\text { Words only } \\
\text { Sounds only } \\
\text { Nil }\end{array}$ & $\begin{array}{l}5 \\
4 \\
3 \\
2 \\
1\end{array}$ \\
\hline Severe head injury (c & $\begin{array}{l}\mathrm{ma})=\mathrm{E} 1, \mathrm{M} 5, \mathrm{~V} 2 \text { or less } \\
\text { (GCS Sumscore } 8 \text { or less with no eye } \\
\text { opening) }\end{array}$ \\
\hline $\begin{array}{l}\text { Moderate head injury } \\
\text { Minor head injury }\end{array}$ & $\begin{array}{l}\text { GCS Sumscore } 9-12 \\
\text { GCS Sumscore } 13-15\end{array}$ \\
\hline
\end{tabular}

A further 5-10\% are suffering from moderate traumatic brain injury, scoring between 9 and 12 on the Glasgow Coma Scale, while the majority (85-90\%) are regarded as having suffered minor traumatic brain injury in terms of their level of consciousness on admission to hospital and score from GCS 13-15..$^{3-5}$ In fact, about a tenth of this latter group, although not obtunded significantly, are harbouring significant skull lesions that may include compound depressed skull fracture, linear skull fracture traversing an air sinus or dural venous sinus or a small penetrating brain wound, each of which carries a potential risk of intracranial infection or haemorrhage.

In addition to the traumatic brain injury, many patients with head injury have extensive injuries elsewhere. In general, the more severe the traumatic brain injury, the greater the incidence of skull fracture and of multiple injury (table 2). ${ }^{6}$

\section{Pathophysiology of traumatic brain injury}

It has been traditional to divide this into primary and secondary brain injuries. Primary brain injury was considered to be more or less complete at the time of impact and to be irreversible. The primary injuries include diffuse axonal injury consisting of scattered division of axons in the white matter of the brain signified within some days of injury by the development of retraction balls, swollen blobs of axoplasm. The distribution of these lesions is considered to be centripetal related to the force of injury so that extension of the lesions from the centrum semiovale down into the brain stem is a marker of an increasing degree of acceleration or deceleration associated with the injury. ${ }^{7}$ The other form of primary brain injury is focal, caused by movement of the brain within the skull and marked by subfrontal and temporal contusions and sometimes lacerations. ${ }^{8}$ An additional form of focal brain injury is the cortical contusion and/or laceration that underlies the site of a direct blow on the skull, particularly if this is sufficiently severe to cause a depressed skull fracture.

The concept of primary diffuse axonal injury may now need to be modified in the light of recent evidence from experimental brain injuries. This suggests that while the brain movement associated with the injury may trigger off an axonal response, the subsequent events are progressive over a period of 
Table 2 Skull fractures, multiple injuries and severity of head injury (Edinburgh head injury admissions for 1981,1986 and 1989)

\begin{tabular}{lllll}
\hline & $\begin{array}{l}\text { Severe } \\
\text { GCS 3-8 }\end{array}$ & $\begin{array}{l}\text { Moderate } \\
\text { GCS 9-12 }\end{array}$ & $\begin{array}{l}\text { Minor } \\
\text { GCS 13-15 }\end{array}$ & $\begin{array}{l}\text { All head } \\
\text { injuries }\end{array}$ \\
\hline Number & 302 & 492 & 3088 & 3882 \\
Linear skull fracture (\%) & $140(46 \%)$ & $152(31 \%)$ & $357(12 \%)$ & $649(17 \%)$ \\
Depressed skull fracture (\%) & $29(10 \%)$ & $9(2 \%)$ & $70(2 \%)$ & $108(3 \%)$ \\
All skull fractures (\%) & $169(56 \%)$ & $161(33 \%)$ & $427(14 \%)$ & $757(20 \%)$ \\
Multiple injuries (\% of number) & $189(63 \%)$ & $183(37 \%)$ & $994(32 \%)$ & $1366(35 \%)$ \\
\hline
\end{tabular}

Note that the majority of patients with depressed skull fracture fall in the minor head injury group. recent detailed survey of 100 patients with severe, moderate and minor head injury associated with other injuries, $92 \%$ of patients were found to have one or more type of intracranial insult occurring for periods of 5 minutes or longer while being managed in a well staffed and well equipped intensive care unit (table 4)..$^{20}$

Secondary brain damage is almost entirely ischaemic in type. It is extremely common and as noted by Graham et al, continues to be found in more than $80 \%$ of fatal head injuries despite modern intensive management. ${ }^{22} 23$ The ischaemic brain damage is, however, arrived at by a variety of intracranial or systemic mechanisms that are indicated in table 3.

Another long held belief was that regeneration did not occur within the damaged CNS. It now appears that following traumatic brain injury there are vigorous attempts at regeneration within the brain, the proximal ends of severed axons produce multiple sprouts, and it is possible that some of the late improvements made by patients with severe diffuse axonal injury may represent successful regeneration. It seems sensible at this stage to at least admit the possibility of regeneration occurring, particularly in patients with diffuse axonal injury in whom there has been no major disruption of the cellular skeleton of

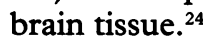

In the light of current understanding of pathophysiology of traumatic brain injury, investigation and treatment of patients with head injury should be directed at early limitation of primary brain damage, prevention of secondary brain damage by early detection and correction of adverse conditions in the form of secondary insults, then maintenance of the patient in an optimal state of perfusion and brain nutrition to provide the most favourable milieu for any regeneration to take place.

Secondary brain insults that may lead to ischaemic brain damage are extremely common after head injuries of all grades of severity, particularly if the head injury is associated with multiple injuries (table 3 ). Thus patients may suffer combinations of hypoxaemia, intracranial hypertension, arterial hypotension, pyrexia and other adverse changes at recurrent intervals in the days following head injury. ${ }^{1617}$ These occur at a time when the normal regulatory mechanism by which the cerebrovascular resistance vessels can relax to maintain an adequate supply of oxygen and blood during such adverse events is impaired as a result of the original trauma. ${ }^{18} 19$ In a

Table 3 Secondary insults to the injured brain

\begin{tabular}{ll}
\hline SYSTEMIC & INTRACRANIAL \\
Hypoxaemia & Haematoma (EDH, SDH, ICH) \\
Arterial hypotension & Brain swelling/oedema \\
Hypercarbia & Intracranial hypertension \\
Severe hypocarbia & Cerebral vasospasm \\
Pyrexia & Intracranial infection \\
$\begin{array}{l}\text { Hyponatraemia } \\
\text { Anaemia }\end{array}$ & Epilepsy \\
Diffuse intravascular & \\
$\quad$ coagulopathy & \\
\hline
\end{tabular}

\section{Assessment and investigation}

The goal of assessment is to discover not only how badly the patient has been injured, but also to determine the risk that further deterioration might supervene.

The assessment of the patient with head injury can begin at the roadside by the ambulance team who can report the obvious injuries, the level of blood pressure and heart rate and score the patient on the Glasgow Coma Scale. Attention to the airway and circulation is of paramount importance during transportation of the patient to the hospital which should be an accident centre with the facilities implied by that term. Unfortunately, many injured patients arrive at the accident centre from the scene of the accident or from other hospitals in shock and/or hypoxic thereby considerably worsening the prognosis. ${ }^{1625}$

Assessing and resuscitating the patient on arrival at the hospital should be done promptly and completely in the Accident and Emergency Department. Security of the airway and stability of the circulation must be 
Table 4 Frequency of secondary insults in 100 head injured patients during intensive care

\begin{tabular}{llll}
\hline Insults type & $\begin{array}{l}\text { Number of } \\
\text { patients } \\
\text { monitored }\end{array}$ & $\begin{array}{l}\text { Number in } \\
\text { whom insult } \\
\text { detected }\end{array}$ & $\begin{array}{l}\text { Percentage } \\
\text { of monitored } \\
\text { patients }\end{array}$ \\
\hline $\begin{array}{l}\text { Raised intracranial } \\
\text { pressure }(>20 \mathrm{~mm} \mathrm{Hg})^{\star}\end{array}$ & 60 & 50 & $83 \%$ \\
$\begin{array}{l}\text { Reduced arterial } \\
\text { pressure }(<70 \mathrm{~mm} \mathrm{Hg})^{\star}\end{array}$ & 91 & 69 & $76 \%$ \\
$\begin{array}{l}\text { Reduced cerebral perfusion pressure } \\
\quad(<60 \mathrm{~mm} \mathrm{Hg})^{\star}\end{array}$ & 58 & 45 & $78 \%$ \\
$\begin{array}{l}\text { Hypoxaemia }\left(\mathrm{SaO}_{2}<90 \% \text { or } \mathrm{PaO}_{2}<8 \mathrm{kPa}\right)^{\star} \\
\text { Hypercarbia }(\mathrm{PaCO}>6 \mathrm{kPa})^{\star}\end{array}$ & 90 & 39 & $43 \%$ \\
Severe hypocarbia $\left(\mathrm{PaCO}_{2}<3 \mathrm{kPa}\right)^{\star}$ & 57 & 17 & $30 \%$ \\
Pyrexia $\left(\mathrm{T}^{\circ}>38\right.$ for more than 1 hour) & 57 & 21 & $35 \%$ \\
\hline
\end{tabular}

ॠFor 5 minutes or more.

assured before the patient is moved anywhere in the hospital for any investigation or treatment, however urgent. All too often, the presence of a severe head injury leads to premature referral of the patient to the Radiology Department for CT before these basic conditions have been fulfilled, leading to predictably disastrous results if arterial hypotension occurs thereafter.

The neurological assessment of a patient with head injury is simplicity itself, consisting of scoring the patient on the Glasgow Coma Scale for the responses of eye-opening, verbal response and motor response to establish the level of consciousness, and noting any side to side difference in motor response so that hemiparesis may be detected. Painful stimuli must be applied above the neck as well as on the limbs, preferably supraorbital and mastoid process pressure, then heavy pressure on the nail beds of the little fingers and toes. This ensures that the lack of limb response due to high spinal cord injury is picked up. The only other essential element of the neurological examination at this stage is the pupillary response to light. Bilateral loss of pupillary light response is indicative of a lesion in the brain stem and is present in $20-25 \%$ of comatose patients with head injury. ${ }^{26}$ Unilateral loss may be due to a lesion of the optic or oculomotor nerves and can be distinguished by comparing direct and consensual responses. Papilloedema is rare despite the fact that raised intracranial pressure is frequent. ${ }^{27}$ Neurological examination is a valid index of brain damage only when blood pressure has been restored to a normal range and the patient is adequately oxygenated. Neurological assessment in the presence of ischaemia and/or hypoxia is unhelpful because it is unknown at that stage whether

Table 5 Intracranial haematoma (all types) vs skull fracture in different severities of head injury

\begin{tabular}{lll}
\hline SEVERE HEAD INJURY & $\begin{array}{l}\text { Haematoma } \\
74(44 \%)\end{array}$ & $\begin{array}{l}\text { No haematoma } \\
94\end{array}$ \\
Fracture & $43(32 \%)^{1}$ & 91 \\
No fracture & & \\
MODERATE HEAD INJURY & $49(29 \%)$ & 118 \\
$\quad$ Fracture & $25(8 \%)^{2}$ & 299 \\
No fracture & & \\
MNOR HEAD INJURY & $42(10 \%)$ & 391 \\
$\quad$ Fracture & $27(1 \%)^{3}$ & 2549 \\
$\quad$ No fracture & & \\
\hline $1 \star \mathrm{X}^{2}=4 \cdot 49 ; \mathrm{p}<0.05$ & & \\
$2 \star \mathrm{X}^{2}=40 \cdot 26 ; \mathrm{p}<0.001$ & & \\
${ }^{3} \mathrm{X}^{2}=123.84 ; \mathrm{p}<0.001$ & &
\end{tabular}

brain dysfunction is due to ischaemia or to injury.

In the patient with head injury it is crucial to discover all other injuries at this early stage of assessment. Pneumothorax or haemothorax need to be detected and treated by chest drainage and if there is any doubt about the possibility of intra-abdominal haemorrhage, then peritoneal lavage should be carried out. In a survey of 60 consecutive patients with severe head injury in whom concomitant trunk injury could not be excluded on history, peritoneal lavage revealed 10 positive cases with confirmation of a significant lesion in all 10 submitted to laparotomy. Only four of these patients were shocked on admission but it must be presumed that the remaining six would have become so had this injury remained undetected..$^{28}$

Radiographs of the skull and a lateral radiograph of the cervical spine should be carried out in the A and E Department. The discovery of a fracture of vault of the skull increases manyfold the risk that this patient, regardless of neurological status, will be harbouring an intracranial haematoma and is therefore an indication for recommending CT (table 5). ${ }^{62930}$ The discovery of a fluid level in the sphenoid sinus or intracranial air are indicative of basal skull fracture. These, and the presence of a depressed skull fracture or penetrating head wound all signal an increased risk of intracranial infection.

CT has provided a major step forward in the management of head injuries in the last two decades. As CT becomes more widely available, the indications for CT after head injury are also widening and continue to yield positive findings. CT should be carried out on all patients with skull fracture, all patients who score below 15 on the Glasgow Coma Scale for 24 hours or more and all patients with seizures or a focal neurological deficit. ${ }^{29}$ Ideally every patient who has sustained a head injury and has been admitted to hospital should have CT. ${ }^{31}{ }^{32}$ In the head injured patient, CT may show an extracerebral haematoma, extradural or subdural; it will also show the amount of brain shift. Midline shift on CT greater than $10 \mathrm{~mm}$ and dilatation of the contralateral ventricle, or a loss of the image of the third ventricle and perimesencephalic cisterns indicate the presence or likelihood of high intracranial pressure (ICP).$^{33-35}$ CT may also show parenchymal lesions of increased density, indicating contusions, usually in the subfrontal and temporal area, deep intracerebral haematomas, and areas of lucency in the case of infarcts, although these become evident only after two or more days.

MRI is more sensitive in showing abnormal brain areas than CT and often yields positive findings in patients who have had what was considered to be only a minor head injury. ${ }^{36}$ Since most of these patients have returned to normality at 6 months, the significance of the MRI findings is uncertain.

Although seldom performed on head injured patients, there remains one important indication for angiography. This is for the 
patient who has an event leading to a head injury that is difficult to explain, where it may be suspected that a stroke or subarachnoid haemorrhage has occurred. Further indications for angiography may be the superimposition of suspected focal brain ischaemia due to traumatic vasospasm, an event that is seldom detected until the infarct has occurred. ${ }^{37}$ Transcranial Doppler sonography may pick up some cases of post-traumatic cerebral vasospasm by documenting an abnormal increase in blood flow velocity in major intracranial vessels. However, such increases can be observed only if the cerebral perfusion pressure is normal. ${ }^{38}$ Thus patients with raised intracranial pressure and vasospasm (a deadly combination) may fail to show increased velocity. Doppler sonography therefore requires to be accompanied by measurement of end tidal $\mathrm{CO}_{2}$ and both arterial and intracranial pressure for correct interpretation of the findings.

\section{Monitoring in patients with severe head injury}

The normal brain requires a constant plentiful supply of blood, oxygen and glucose and, within limits, the resistance vessels of the cerebral circulation can respond by appropriate alterations of vascular calibre to alterations in perfusion pressure and the arterial tensions of oxygen and carbon dioxide. In the injured brain, these regulatory mechanisms are impaired. ${ }^{1819} \mathrm{~A}$ prime purpose of monitoring head injured patients is to measure continuously the arterial and intracranial pressure, the components of cerebral perfusion pressure $(\mathrm{CPP}=\mathrm{BP}-\mathrm{ICP})$ and arterial oxygenation. ${ }^{39}$ With this knowledge, levels can be adjusted to provide optimal perfusion and nutrition of the brain even when the normal regulatory mechanisms are impaired and cerebrovascular resistance is increased. Definition of these optimal levels is not straightforward, however, since these vary between patients and within individual patients over time. Another purpose of patient monitoring is to assess the effect of systemic events on brain function in a patient who is inaccessible to clinical evaluation.

In all patients with severe head injury, after a clear airway and adequate ventilation have been assured, arterial pressure should be monitored using an indwelling arterial cannula to provide a continuous record as well as convenient access for intermittent measurement of arterial blood gases. Arterial oxygen saturation should be monitored continuously using pulse oximetry. The issue of whether or not to monitor ICP is more controversial because current techniques are invasive and carry a risk of morbidity from intracranial infection (2-8\%), intracranial haemorrhage (less than 1\%) and epilepsy (less than 1\%).41 If it is accepted, however, that the cerebral perfusion pressure is important and that levels of arterial pressure are meaningless unless intracranial pressure is also known, then logic dictates that ICP should be monitored.
Cerebral perfusion pressure is calculated from the difference between mean arterial and mean intracranial pressure using diastolic plus one third of pulse pressure or an electronically integrated mean pressure value. Recent studies indicate that a frequency of raised intracranial pressure of $80 \%$ or more is found in comatose head injured patients. ${ }^{21} 42$ While CT signs, such as, loss of image of the third ventricle and perimesencephalic cisterns, are highly suggestive that ICP is, or will become, elevated, the absence of these findings is no guarantee of normal ICP. In eight severely head injured patients in whom admission CT showed no such indications of raised ICP, intracranial hypertension ensued in all but one case (unpublished data).

ICP may be monitored by insertion of an intraventricular fluid filled catheter or by insertion of a solid state fibre optic system into brain parenchyma, the lateral ventricle or the sub dural space. ${ }^{43}$ ICP should be monitored for three days after severe brain injury to cover the expected duration of formation of post traumatic brain oedema and swelling. ICP monitoring can be continued for as long as episodes of intracranial hypertension occur and is normally discontinued after 48 hours of normal pressure recording.

In patients with severe head injury in whom raised intracranial pressure is anticipated and particularly when treatment is required, much valuable information can be obtained from continuous monitoring of jugular venous oxygen saturation $\left.\left(\mathrm{JvSO}_{2}\right)\right)^{404445}$ This can now be measured continuously using an indwelling fibre optic catheter system that requires to be precalibrated then calibrated in situ every 12 hours against measurements made by cooximetry on withdrawn blood samples. JvSO, should lie in the range of $55-85 \%$. Values above $85 \%$ are indicative of cerebral hyperaemia. Values below $55 \%$ indicate increasing cerebral oxygen extraction, may occur when cerebral blood flow is reduced, and values below $45 \%$ indicate global cerebral ischaemia.

Continuous monitoring of brain electrical activity is valuable in the monitoring of the comatose head injured patient who is being artificially ventilated under the influence of muscle relaxant drugs. In such patients only the pupil light responses are available as an assessment of a neurological function. Continuous measurements of EEG wave amplitude or frequency are helpful but need to be interpreted in the light of drug administration.

Velocity of blood flow in the intracranial arteries, notably the middle cerebral artery, can be measured intermittently or continuously for periods of several hours using transcranial Doppler sonography. With decreasing cerebral perfusion pressure, mean flow velocity decreases from the normal value of $55-65 \mathrm{~cm} / \mathrm{s}$ but diastolic flow velocity decreases more than systolic flow velocity. ${ }^{40} 46$ As a result, the pulsatility index, a dimensionless figure derived from the difference between systolic and diastolic flow velocity 
divided by mean flow velocity, increases from the normal value of around unity to three or more. Combined measurements of cerebral perfusion pressure, Doppler measurement of pulsatility index and $\mathrm{JvSO}_{2}$ in patients with severe head injury have shown that below a threshold perfusion pressure level of $70 \mathrm{mmHg}$, pulsatility index starts to increase and $\mathrm{JvSO}_{2}$ starts to fall. ${ }^{40}$ At perfusion pressure greater than $70 \mathrm{mmHg}$ there is no further increase in $\mathrm{JvSO}_{2}$ suggesting that while a CPP level of $70 \mathrm{mmHg}$ is optimal for the head injured patient, the achievement of higher levels does not confer further advantage.

Doppler flow velocities may also be abnormally high $(>100 \mathrm{~cm} / \mathrm{s})$ in the patient with head injury at perfusion pressure level of $70 \mathrm{mmHg}$ or above. ${ }^{38}$ Such increased velocity may be due to a true increase in volume flow that would be signalled by an increase in $\mathrm{JvSO}_{2}$ over $85 \%$, or they may be caused by narrowing of the insonated vessels, cerebral vasospasm. In the latter case, $\mathrm{JvSO}_{2}$ may be normal or low. While measurement of $\mathrm{JvSO}_{2}$ can be used in this way to distinguish vasospasm from hyperaemia, it appears that inspection of the Doppler waveform can also provide this information, non-hyperaemic patients showing a dicrotic notch on the descending arm of the Doppler wave, while hyperaemic patients do not show such a notch. ${ }^{47}$

Management of patients with head injury The goal of management of these patients is to prevent wherever possible the occurrence of secondary insults to the injured brain, both intracranial and systemic, and where this is not possible, to detect such insults as early as possible and reverse them. The injured brain is extremely vulnerable to such insults, for example, a single episode of arterial hypotension or raised intracranial pressure lasting only a few minutes may be sufficient to arrest the cerebral circulation which then fails to reestablish even when normal pressures have been regained and brain death ensues. Experimental data confirm this additive effect. ${ }^{48}$ For this reason, a pre-emptive approach to head injury management is essential, aiming to identify patients and situations that carry a high risk of development of insults.

To ensure that the airway is clear and ventilation adequate, early endotracheal intubation and artificial ventilation is increasingly being employed to cover patients during transportation between hospitals and within the hospital, for example, between the Accident and Emergency Department and CT imaging. It is crucial therefore that the level of consciousness of the patient be reliably assessed before the administration of sedative and/or relaxant drugs. In addition to assessing the severity of head injury, the earliest opportunity should be taken to assess the patient for any other injuries. Multiple injuries are present in more than $50 \%$ of patients with severe head injury and in a substantial proportion of patients with less severe injury. In a comatose patient it is important to exclude intra-abdominal bleeding, if necessary by peritoneal lavage, or mini-laparotomy, rather than await the onset of arterial hypotension. When arterial hypotension (systolic BP $<90 \mathrm{mmHg}$ ) is present it must be assumed that it is due to other injuries rather than to brain injury.

Patients with skull fracture and/or depressed level of consciousness, abnormal neurological signs or early seizures should all have CT imaging as soon as possible, even if this means transfer from one hospital to another. More than $40 \%$ of comatose patients with head injury have intracranial haematomas and it is now clear that there are no clinical signs that allow the clinician to distinguish reliably between patients with intracranial haematomas and those with diffuse brain injury and swelling. While it has been argued that transport of head injured patients from one hospital to another can be hazardous and time consuming, a recent study indicates that most delay occurs within the referring hospital because of slow recognition that the patient is at risk from intracranial bleeding. ${ }^{49}$

It cannot be emphasised enough that patients should be moved from the resuscitation area of the Accident and Emergency Department only when the airway is secure and the circulation stable. If a stable circulation cannot be obtained, it must be assumed that the patient has occult intra-abdominal or other haemorrhage and steps must be taken to diagnose this by peritoneal lavage and correct it, whether by surgery or endovascular approaches. This takes precedence over the performance of CT scanning and any intracranial surgery and in such cases CT should be deferred until the systemic emergency has been dealt with.

\section{Aspects of surgical management}

In cases where CT imaging reveals an intracranial haematoma, the next decision is whether surgical evacuation is required. As a general rule, urgent evacuation of extracerebral haematomas that are associated with $5 \mathrm{~mm}$ or more of midline shift and/or are $25 \mathrm{mls}$ or more in calculated volume should be carried out. The younger the patient the more ready the surgeon should be to evacuate a haematoma because of the less compliant nature of the craniospinal contents.

In cases where the extracerebral (extradural or subdural) haematoma is considered to be too small to warrant surgical evacuation, it is essential that CT scanning be repeated after a few hours in all patients in whom the first CT scan has been carried out within six hours of injury. A significant number of such early diagnosed extradural haematomas will be found to have expanded considerably over the ensuing few hours, and it is in keeping with the pre-emptive approach to management that these haematomas be 
diagnosed before the patient manifests clinical signs of distress. ${ }^{50}$

The role of early operative treatment in the management of intracerebral haematomas and haemorrhagic contusions is more controversial. ${ }^{26}$ While some advocate early surgery in such cases, experience has shown that despite surgical treatment, post-operative intracranial hypertension continues to occur in virtually all patients and a growing number of neurosurgeons prefer to manage such patients conservatively at first, relying upon continuous monitoring of arterial and intracranial pressure and repeat CT scanning to pick up those cases in which a progressive increase in pressure and an increase in mass effect may warrant delayed operative evacuation of the haematoma.

In comatose patients in whom a sizeable extracerebral haematoma is disclosed, it is important that the brain be decompressed as soon as possible. A standard practice is to administer a large bolus dose of mannitol solution, $1 \mathrm{~g} / \mathrm{kg}$ bodyweight, rapidly while the patient is still in the CT imaging suite, then to transport the patient to operating theatre and to proceed as quickly as possible to the point where the skull can be opened and haematoma evacuated from the extradural or subdural space. In this situation, minutes count but it is also important that decompression is effective and this usually demands more access than can be gained by a burr hole.

The other situation in which neurosurgical procedures may be required soon after injury is for complex head wounds such as a compound depressed skull fracture, particularly when dural tearing is involved as it is in $50 \%$ of cases. ${ }^{51}$ While it is important that debridement of the wound, removal of haematoma or contaminating foreign matter and sound wound closure be obtained quickly to avoid infection there is not the same degree of urgency about these procedures as is necessary for evacuation of intracranial haematoma. ${ }^{52}$ It is sensible for the team to take up to six hours if that is necessary to obtain the best possible operating conditions to minimise the extent of any brain swelling and possible extrusion of brain tissue of doubtful viability through the compound wound.

\section{Non-operative management}

In patients managed by artificial ventilation, arterial $\mathrm{PCO}_{2}$ is kept in the range 3.5 to 4.5 $\mathrm{kPa}$ and $\mathrm{SaO}_{2}$ should be kept as close to $100 \%$ as possible, employing where necessary an increase in $\mathrm{FiO}_{2}$ and positive end expiratory pressure (PEEP). Arterial pressure should not be allowed to fall. The common causes of arterial hypotension are unsuspected hypovolaemia due to inadequate fluid replacement and the administration of sedative drugs such as barbiturates and propofol. The combination of hypovolaemia and sedative drug administration is particularly dangerous..$^{53} 54$

Intracranial pressure should ideally be held below $20 \mathrm{mmHg}$. Moderate increases to $25 \mathrm{mmHg}$ or even $30 \mathrm{mmHg}$ may be tolerated provided arterial pressure is sufficient to yield a cerebral perfusion pressure of $70 \mathrm{mmHg}$ or more. When ICP rises above $25 \mathrm{mmHg}$ checks should be made for simple causes of intracranial hypertension such as excessive flexion or rotation of the neck, obstruction of the airway, loss of effect of relaxant drugs with the patient making respiratory efforts against the ventilator, elevations in arterial $\mathrm{PCO}_{2}$ or body temperature, or occult epileptic seizures. ${ }^{55}$ In patients receiving muscle relaxants seizures may be difficult to detect but may be signalled by bilateral pupillary dilatation and a small increase in arterial pressure accompanied by a larger increase in ICP. One of the advantages of continuous recording of brain electrical activity is that it becomes easier to detect such seizures.

Another important cause of intracranial hypertension is water overload causing dilutional hyponatraemia. ${ }^{56} 57$ The most important surgical cause of intracranial hypertension is development of an intracranial mass lesion due to delayed haemorrhage or development of brain oedema and swelling. Surgical decompression may be required to reduce brain shift and distortion as well as reducing ICP.

When ICP rises above $25 \mathrm{mmHg}$ within the first 48 hours after injury, or $30 \mathrm{mmHg}$ thereafter and CPP is threatened, specific therapy may be required to reduce ICP if simple corrective measures have been applied and failed. ICP therapy should ideally be directed at the cause of the increase in pressure, which may be divided simply into vascular and non-vascular causes. In the case of vascular intracranial hypertension there is vasodilation with an increase in volume of blood in the capillary and venous beds and the most appropriate therapy is one that will reduce the calibre of the cerebral resistance vessels. The simplest measure is hyperventilation with further reduction of arterial $\mathrm{PCO}_{2}$ to $3.5 \mathrm{kPa}$ with the aim of inducing some cerebral vasoconstriction. While this is often a useful temporary measure the effect cannot be long lasting and there is a real risk that excessive cerebral vasoconstriction may result in ischaemia. ${ }^{58}$ In this situation continuous monitoring of $\mathrm{JvSO}_{2}$ is valuable. Excessive hyperventilation that produces cerebral ischaemia will be rapidly signalled by a fall in $\mathrm{JvSO}_{2}$ to less than $45 \%$. For a longer lasting effect, infusion of sedative or hypnotic drugs can be used, thiopentone sodium or propofol. These drugs are most effective if cerebrovascular $\mathrm{CO}_{2}$ reactivity is preserved. ${ }^{59}$ The use of these drugs must be very carefully monitored because of their effect on blood pressure. Again, continuous monitoring of $\mathrm{JvSO}_{2}$ will provide immediate indication if a moderate reduction in arterial blood pressure is sufficient to cause global cerebral ischaemia. This is a signal to reduce the infusion rate of the sedative drug, or even stop it altogether. Indomethacin infusion is under investigation 
as an alternative means of reducing raised ICP. 60

In the case of intracranial hypertension of non-vascular origin, due to brain oedema, the most appropriate therapy is intravenous mannitol solution. When given for this purpose the lowest dose of mannitol should be used that is sufficient to lower ICP and improve cerebral perfusion pressure. As a rough guide a starting dose of $0.5 \mathrm{gm} / \mathrm{kg}$ body weight should be used and subsequent doses adjusted upwards or downwards as determined by the response of ICP and CPP. The effect may be enhanced by administering frusemide while mannitol is being given and following the mannitol by albumen infusion. ${ }^{6162}$ Mannitol solution should not be administered if the serum osmolality is greater than $320 \mathrm{mOsm} / \mathrm{L}$ as it will not only be ineffective but carries a grave risk of producing renal failure. On occasion it may be necessary to support the arterial blood pressure with pressor agents to maintain an adequate level of CPP. At present there is no consensus on the best pressor agent to employ.

\section{Drug therapy and head injury}

There is no place for steroid therapy as a treatment for brain injury or for acute posttraumatic brain oedema. Numerous trials of steroids at various doses have produced either negative or inconclusive results and one study recorded an adverse effect of steroids in patients with severe head injury with raised ICP. .364

At present, trials are underway on the effect of various neuroprotective drugs, calcium ion channels or NMDA-type glutamate receptor blocking agents or anti-oxidants acting in the cell membrane. While there is promising information from experimental studies, firm conclusions have not yet been reached on the value of neuroprotective agents in head injured patients. ${ }^{15}$

Prophylactic anticonvulsant drugs are no longer in vogue in the treatment of head injury following trials where no convincing preventative effect was shown. Post-traumatic epilepsy is, however, not uncommon. When it does occur later than one week from the time of injury then patients should be started on appropriate anticonvulsant drug therapy.

Similar controversy exists on the role of prophylactic antibiotic therapy in the case of patients with intracranial air, CSF rhinnorrhoea or otorrhoea and who are therefore at increased risk of developing meningitis after head injury. Opinions on the value of prophylactic antibiotics are sharply divided, with forceful opinions both for the need to provide adequate antibiotic prophylaxis and the opposing school which argues that such treatment only encourages the development of antibiotic resistant strains of bacteria.

\section{Outcome from head injury}

With increasing understanding of the pathophysiology of primary and secondary brain injury and the adoption of a pre-emptive approach to patient management based upon knowledge of risk factors for development of secondary brain damage, the mortality of severe head injury has fallen from $50 \%$ to between $30 \%$ and $40 \%$ over the past two decades. ${ }^{265}$ The proportion of patients with severe head injury who remain severely disabled at six months or longer following head injury remains disappointingly at $10-20 \%$ while only a small number of patients survive in the persistent vegetative state. At six months or later only $1-3 \%$ of severely injured patients fall into this category. The remaining surviving patients divide more or less equally into those who make good recovery and return to the pre-injury level of function, even though there may be small residual deficits, and moderately disabled patients who, although independent for activities of daily living, do not ever return to their previous level of function. The challenge of the last years of this century will be to reduce the disability suffered by the survivors of severe and moderate head injury and thus improve the quality of life for these patients and their families.

One difficulty is that factors that predict increased mortality such as advancing age, low coma score and signs of brain stem dysfunction, are less effective in predicting disability in survivors. ${ }^{667}$ There is a suggestion that secondary insults such as intracranial hypertension and low CPP are not only associated with higher mortality but are also associated with an increase in severe disability. ${ }^{26}$ It remains to be determined whether reduction in the burden of secondary insults suffered by patients with head injury will diminish disability in survivors.

1 Kalsbeek WD, McLaurin RL, Harris BSH, Miller JD. The National Head and Spinal Cord Injury Surgery: Major findings. F Neurosurg 1980;53 (Suppl):S19-S31.

2 Jennett B, McMillan R. Epidemiology of head injury. $B M \mathcal{F} 1981 ; 282: 101-4$

3 Teasdale G, Jennett B. Assessment of coma and impaired consciousness. Lancet 1974;2:81-4.

4 Miller JD, Jones PA. The work of a regional head injury service. Lancet 1985;1:1141-4

5 Miller JD, Jones PA, Dearden NM, Tocher JL. Progress in the management of head injury. Brit $\mathcal{F}$ Surg 1992; in the man.

6 Miller JD. Minor, moderate and severe head injury. Neurosurg Rev 1986;9:135-9.

7 Adams JH, Mitchell DE, Graham DI, Doyle D. Diffuse brain damage of immediate impact type. Brain 1977; 100:489-502.

8 Adams JH. Head injury. In: Hume-Adams J, Corsellis JAN, Duchen LW, eds. Greenfield's neuropathology, 4th ed. London: Edward Arnold, 1984:85-124.

9 Yaghmai A, Povlishock J. Traumatically induced reactive change as visualised through the use of mono-clonal antibodies targeted to neurofilament subunits. $\Im$ Neuropath Exp Neurol 1992;51:158-76.

10 Povlishock JT. Traumatically induced axonal injury: pathogenesis and pathobiological implications. Brain Pathology 1992;2:1-12.

11 Kontos HA, Wei EP. Superoxide production in experimental brain injury. $\mathcal{F}$ Neurosurg 1986;64:803-7.

12 Ikeda Y, Long DM. The molecular basis of brain injury and brain edema: the role of oxygen free radicals. Neurosurgery 1990;27:1-11.

13 Hayes RL, Stonnington HW, Lyeth BG, Dixon CE, Yamamoto T. Metabolic and neurophysiologic sequelae of brain injury. A cholinergic hypothesis. F Central Nervous System Trauma 1986;3(2):163-73.

14 Wahl M, Unterberg A, Baethmann A, Schilling L. Mediators of blood-brain barrier dysfunction and formation of vasogenic brain edema. $\mathcal{F}$ Cereb Blood Flow Metabol 1988;8:621-34.

15 Hall ED. The neuroprotective pharmacology of methyl 
prednisolone. F Neurosurg 1992;76:13-22.

16 Miller JD, Sweet RC, Narayan R, Becker DP. Early insults to the injured brain. F Am Med Ass 1978;240: 4319-442.

17 Miller JD, Becker DP. Secondary insults to the injured brain. $\mathcal{f}$ Roy Coll Surg Ed 1982;27:292-8.

18 Lewelt W, Jenkins LW, Miller JD. Autoregulation of cerebral blood flow after experimental fluid percussion injury of the brain. $\mathcal{F}$ Neurosurg 1980;53:500-11.

19 Lewelt W, Jenkins LW, Miller JD. Effects of experimental fluid percussion injury of the brain on cerebrovascular reactivity to hypoxia and hypercapnia. $\mathcal{f}$ Neurosurg 1982;56:332-8.

20 Andrews PJD, Piper IR, Dearden NM, Miller JD. Secondary insults during intrahospital transport of head injured patients. Lancet 1990;335:327-30.

21 Jones PA, Andrews PJD, Midgley S, et al. Assessing the burden of secondary insults in head injured patients during intensive care (SBNS Abstract). $f$ Neurol Neurosurg Psychiatry. (In press.)

22 Graham DI, Adams JH, Doyle D. Ischaemic brain damage in fatal non-missile head injuries. I Neurol $\mathrm{Sci}$ 1978;39:213-34.

23 Graham DI, Ford I, Hume-Adams J, Doyle D, Teasdale GM, Lawrence AE, McLellan DR. Ischaemic brain damage is still common in fatal non-missile head injury. F Neurol Neurosurg Psychiatry 1989;52:346-50.

24 Povlishock JT, Erb DE, Astruc J. Axonal response to traumatic brain injury: reactive axonal change, deafferentation and neuroplasticity. $\mathcal{F}$ Neurotrauma 1992;9: (Suppl 1):S189-S200.

25 Gentleman D, Jennett B. Audit of transfer of unconscious head injured patients to a neurosurgical unit. Lancet 1990;335:330-4.

26 Miller JD, Butterworth JF, Gudeman SK, et al. Further experience in the management of severe head injury. experience in the managem
$\mathcal{N}$ Neurosurg 1981;54:289-99.

27 Selhorst JB, Gudeman SK, Butterworth JF, Harbison JW, Miller JD, Becker DP. Papilledema after acute head injury. Neurosurgery 1985;16:357-63.

28 Butterworth JF, Maull KI, Miller JD, Becker DP. Detection of occult abdominal trauma in patients with severe head injuries. Lancet 1980;2:759-62.

29 Teasdale GM, Murray G, Anderson E, Mendelow AD, MacMillan R, Jennett B, Brookes M. Risks of acute traumatic intracranial haematoma in children and adults: implications for managing head injuries. $B M F$ 1990;300:363-7.

30 Chan KH, Mann KS, Yue CP, Fan YW, Cheung M. The significance of skull fracture in acute traumatic intracranial hematomas in adolescents: a prospective study. f Neurosurg 1990;72:189-94.

31 Bricolo AP, Pasut LM. Extradural haematoma: towards zero mortality. Neurosurgery 1984;14:8-12.

32 Servadei F, Piazza G, Seracchioli A, Acciarri N, Pozzati E, Gaist G. Extradural haematomas: an analysis of the changing characteristics of patients admitted from 1980 to 1986. Diagnostic and therapeutic implications in 158 cases. Brain Injury 1988;2:87-100.

33 Teasdale E, Cardoso E, Galbraith S, Teasdale G. CT scan in severe diffuse head injury: physiological and clinical consultations. $f$ Neurol Neurosurg Psychiatry 1984;47:600-3.

34 Colquhoun IR, Burrows EH. The prognostic significance of the third ventricle and basal cisterns in severe closed head injury. Clin Radiol 1989;40:13-6.

35 Marshall LF, Marshall SB, Klauber MR, et al. A new classification of head injury based on computerised tomography. $\mathcal{F}$ Neurosurg 1991;75:S14-S20.

36 Levin HS, Amparo E, Eisenberg HM, Williams DH, High WM, McArdle CB, Weiner RL. Magnetic resonance imaging and computerised tomography in relation to the neurobehavioural sequelae of mild and moderate head injuries. $\mathcal{f}$ Neurosurg 1987;66:706-13.

37 Macpherson P, Graham DI. Correlation between angiographic findings and the ischaemia of head injury. ๆ Neurol Neurosurg Psychiatry 1978;41:122-7.

38 Chan KH, Dearden NM, Miller JD. The significance of post-traumatic increase in cerebral blood flow velocity: a transcranial doppler ultrasound study. Neurosurgery 1992;30:697-700

39 Miller JD, Stanek AE, Langfitt TW. Concepts of cerebral perfusion pressure and vascular compression during perfusion pressure and vascular compression during Progress in brain research, vol 35: cerebral blood flow. Progress in brain research, vol 35.

40 Chan $\mathrm{KH}$ Miller JD, Dearden NM, Andrews PJD, Midgley S. The effect of changes in cerebral perfusion pressure upon middle cerebral artery blood flow velocity and jugular venous oxygen saturation after severe brain injury. F Neurosurg 1992;77:55-61.

41 Lundberg $N$. Continuous recording and control of ventricular fluid pressure in neurosurgical practice. Acta Psychiat Neurol Scand 1960;36:(Suppl 149) 1-193.

42 Marmarou A, Anderson RL, Ward JD, et al. Impact of
ICP instability and hypotension on outcome in patients with severe head trauma. 7 Neurosurg 1991;75:S59-S66.

43 Crutchfield JS, Narayan RK, Robertson CS, Michael LH. Evaluation of a fibreoptic intracranial pressure monitor. F Neurosurg 1990;72:482-7.

44 Dearden NM. Jugular bulb venous oxygen saturation in the management of severe head injury. Current Opinion in Anaesthesiology 1991;4:279-86.

45 Sheinberg M, Kanter MJ, Robertson CS, Contant CF Narayan RK, Grossman RG. Continuous monitoring of jugular venous oxygen saturation in head injured patients. $\mathcal{F}$ Neurosurg 1992;76:212-7.

46 Chan KH, Miller JD, Dearden NM. Intracranial blood flow velocity after head injury: relationship to severity of injury, time, neurological status and outcome. $\mathcal{F}$ Neurol Neurosurg Psychiatry 1992;55:787-91.

47 Chan KH, Dearden NM, Miller JD, Piper IR. Transcranial Doppler waveform differences in hyperaemic and non-hyperaemic patients after severe head injury. Surgical Neurology 1992;38:433-6.

48 Jenkins LW, Moszynski K, Lyeth BG, et al. Increased vulnerability of the mildly traumatised rat brain to cerebral ischemia: the use of controlled secondary ischemia as a research tool to identify common or different mechanisms contributing to mechanical and ischemic brain injury. Brain Research 1989;477:211-24.

49 Marsh H, Maurice-Williams R, Hatfield R. Closed head injuries: where does delay occur in the process of transfer to neurosurgical care? Brit $f$ Neurosurg 1989;3:13-20.

50 Knuckey NW, Gelbard S, Epstein MH. The management of "asymptomatic" epidural hematomas. A prospective study. F Neurosurg 1989;70:392-6.

51 Miller JD, Jennett B. Complications of depressed skull fractures. Lancet 1968;ii:991-5.

52 Sutcliffe JC, Miller JD, Whittle IR, Steers AJW. Gas gangrene occurring soon after compound depressed skull fracture. Acta Neurochir 1988;95:53-6.

53 Schwart ML, Tator CH, Rowed DW, Reid SR, Megura $\mathrm{K}$, Andrews DF. The University of Toronto Head Injury treatment study: a prospective randomised comparison of pentobarbital and mannitol. Canad $\mathcal{F}$ Neurol Sci 1984;11:434-40.

54 Ward JD, Becker DP, Miller JD, et al. Failure of prophylactic barbiturate coma in the treatment of severe head injury. F Neurosurg 1985;62:383-8.

55 Miller JD, Dearden NM, Piper IR, Chan KH. Control of intracranial pressure in patients with severe head injury. 7 Neurotrauma 1992;9:(Suppl 1):S317-26.

56 Arieff AI. Hyponatremia associated with permanent brain damage. Adv Intern Med 1987;32:325-44.

57 Bertrand YM, Herman A, Mahieu P, Roels J. Intracrania pressure changes in patients with head trauma during pressure changes in patients with head trauma during

58 Muizelaar JP, Marmarou A, Ward JD, et al. Adverse effects of prolonged hyperventilation in patients with severe head injury: a randomised clinical trial. f Neurosurg 1991;75:731-9.

59 Nordstrom CH, Messeter K, Sundbarg G, Schalen W, Werner M, Ryding E. Cerebral blood flow, vasoreactivity and oxygen consumption during barbiturate therapy 424-31.

60 Jensen K, Ohrstrom J, Cold JE, Astrup J. The effects of indomethacin on intracranial pressure, cerebral blood flow and cerebral metabolism in patients with severe head injury and intracranial hypertension. Acta head injury and intracranir

61 Roberts PA, Pollay M, Engles C, Pendleton B, Reynolds E, Stevens FA. Effect on intracranial pressure of furosemide combined with varying doses and administration rates of mannitol. $₹$ Neurosurg 1987;66:440-6.

62 Albright AL, Latchaw RE, Robinson ÁG. Intracranial and systemic effects of osmotic and oncotic therapy in experimental cerebral edem. $f$ Neurosurg 1984;60 481-9.

63 Braakman R, Schouten HJD, Van Dishoeck BM, Minderhoud JM. Megadose steroids in severe head injury results of a prospective double blind clinical trial. f Neurosurg 1983;58:326-30.

64 Dearden NM, Gibson JS, McDowall DG, Gibson RM, Cameron MM. Effect of high dose dexamethasone on outcome from severe head injury. $f$ Neurosurg outcome from

65 Marshall LF, Gautille T, Klauber MR, et al. The outcome of severe closed head injury. $\mathcal{F}$ Neurosurg 1991;75: S28-S36.

66 Jennett B, Teasdale G, Braakman R, Minderhoud J, Heiden J, Kurze T. Prognosis of patients with severe head injury. Neurosurgery 1979;4:283-9.

67 Braakman R, Gelpke GJ, Habbema JDF, Maas AIR, Minderhoud J. Systematic selection of prognostic features in patients with severe head injury. Neurosurgery 1980;6:362-70. 